\title{
CORRIGENDUM
}

\section{Cryptic species within Anopheles longipalpis from southern Africa and phylogenetic comparison with members of the $A n$. funestus group - CORRIGENDUM}

\section{L.L. Koekemoer, E.A. Misiani, R.H. Hunt, R.J. Kent, D.E. Norris and M. Coetzee}

doi:10.1017/S0007485308006123, Published by Cambridge University Press, 22 August 2008

Subsequent to the work completed for this paper, additional samples were received and processed from other localities. Our conclusion that primer $\mathrm{C} 1$ does not amplify the DNA of other members of the Anopheles funestus group as stated in the legend to fig. 6 is incorrect. We caution, therefore, against the use of the An. longipalpis primer on any specimens other than those that do not amplify using the standard PCR for identification of members of the An. funestus group. Additional molecular analysis is currently underway.

\section{Reference}

Koekemoer, L.L., Misiani, E.A., Hunt, R.H., Kent, R.J., Norris, D.E. \& Coetzee, M. (2009) Cryptic species within Anopheles longipalpis from southern Africa and phylogenetic comparison with members of the An. funestus group. Bulletin of Entomological Research 99, $41-49$. 